


\title{
REUSABLE LAUNCH VEHICLE TANK/NTERTANK SIZING TRADE STUDY
}

\author{
John T. Dorsey", David E. Myers", Carl J. Martin ${ }^{\ddagger}$ \\ NASA Langley Research Center \\ Hampton, VA
}

\begin{abstract}
A tank and intertank sizing tool that includes effects of major design drivers, and which allows parametric studies to be performed, has been developed and calibrated against independent repzresentative results. Although additional design features, such as bulkheads and field joints, are not currently included in the process, the improved level of fidelity has allowed parametric studies to be performed which have resulted in understanding of key tank and intertank design drivers, design sensitivities, and definition of preferred design spaces. The sizing results demonstrated that there were many interactions between the configuration parameters of internal/external payload, vehicle fineness ratio (half body angle), fuel arrangement (LOX-forward/LOX-aft), number of tanks, and tank shape/arrangement (number of lobes).
\end{abstract}

\section{INTRODUCTION AND TRADE STUDY OBJECTIVES}

Future launch vehicles must be lightweight, fully reusable and easily maintained if low-cost access to space is to be achieved. The X-33 Program is a joint venture between NASA and Lockheed Martin to develop the enabling technologies for such a vehicle with a goal of reducing the cost of placing payloads into orbit by an order of magnitude. ${ }^{\prime}$ The Lockheed Martin Venture-

"Aerospace Engineer, Metals \& Thermal Structures Branch, Structures and Materials Competency, Senior Member AIAA.

${ }^{\dagger}$ Aerospace Engineer, Vehicle Analysis Branch, Aerospace Systems Concepts and Analysis Competency, Member AIAA.

${ }^{\ddagger}$ Aerospace Engineer, Metals \& Thermal Structures Branch, Structures and Materials Competency, Currently Researcher in College of Engineering. University of Wisconsin (Madison), Member AIAA.

Copyright (1) 1999 American Institute of Aeronautics and Astronautics, Inc. No copyright is asserted in the United States under Title 17, U.S. Code. The U.S. Government has a royaltyfree license to exercise all rights under the copyright claimed herein for Governmental purposes. All other rights are reserved by the copyright owner.
Star ${ }^{\mathrm{TM}}$, a proposed commercial Reusable Launch Vehicle (RLV) based on the X-33 configuration, is a lifting body with aerospike engines mounted aft (Figure 1). The goal of VentureStar ${ }^{\mathrm{TM}}$ is to establish a vehicle that meets targets for empty weight, payload to orbit, and stability through all flight regimes, while being economically viable. Currently, parametric weights are being used to assess the viability of configurations as changes are made to the vehicle Outer Mold Line (OML) and major changes are made in the vehicle structural arrangement. For example, the number of cryogenic tanks (as well as their shapes, sizes and packaging) vary widely between possible configurations, as does the location of the payload bay, connection of tanks through intertanks, and integration of tanks into the thrust structure. However, current parametric weights lack the fidelity to allow discrimination between different arrangements, configurations, sizes and geometries of major airframe structural components. They also offer no insight into defining either the major structural parameters driving a design, or sensitivity of a particular structural concept to its design drivers. As a result major perturbations have been made to the vehicle structure, and the erroneous result of no apparent impact on the vehicle total weight was obtained.

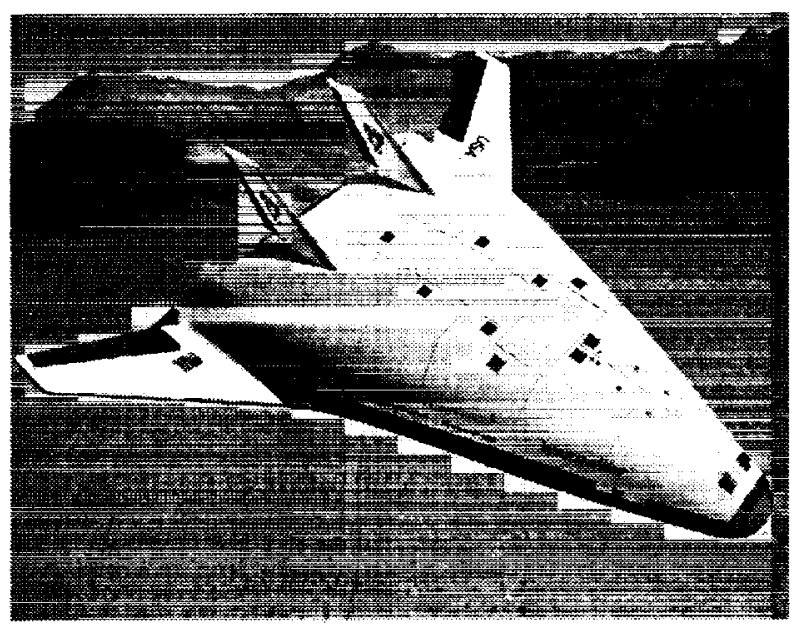

Figure 1. Lifting body reusable launch vehicle configuration. 
The current trade studies focused on developing preliminary weight estimates for the cryogenic fuel tanks and connecting intertanks for a VentureStar ${ }^{\mathrm{TM}}$-class Single Stage to Orbit (SSTO) lifting body RLV. The study had the following three objectives:

1) Develop increased fidelity parametric structural analysis and sizing relationships for RLV tank and intertank structural components that include major design drivers as variables, including geometry, pressure (ullage and head), shape, dimensions, and "non-optimums" such as joints. Relationships would also allow a limited amount of structural tailoring, to capture the benefits of adjusting the design to the load gradients within a particular structural component.

2) Size and compare tank and intertank structural weights of nominally equivalent vehicles, that is, with equal total Liquid Oxygen (LOX) and Liquid Hydrogen (LH2) volumes, but having different configuration definitions.

3) Parametrically assess and define design conditions (such as tank wall thickness constraints and ullage pressures) that result in one configuration being lighter in weight than the other.

\section{VEHICLE CONFIGURATIONS AND TANKJ INTERTANK GEOMETRIES}

\section{Major Features}

Many different tank geometries and packaging arrangements can be accommodated in a lifting body shape RLV like that shown in Figure 1. A total of 7 different tank geometry and packaging configurations, as shown in Figure 2, were assessed in this trade study. Three were generated by the Lockheed Martin Skunkworks [LMSW] (the 0023,0033 and 0028 ) and four were generated by the Langley Research Center [LaRC] team (the LAI [LOX-aft 1], HFLF [high fineness LOX-forward], LL1B [LaRC Lifting body 1B], and LL401 [LaRC Lifting body 401]). The major features represented in the configurations include: LOX tank forward and LOX tank aft; variations in vehicle fineness ratio; payload bay internal, 50 percent external and 100 percent external; variations in the number of tanks; and variations in the number of lobes in the lobed tanks.

The LMSW 0023 configuration (Figure 2a) tank packaging is the same as for the reference vehicle $0002 \mathrm{~A},{ }^{2}$ has an internal arrangement that is similar to the $\mathrm{X}-3.3$, and is the point of departure for the various configuration perturbations being considered in the present study. The body half angle for the 0023 is 20 degrees. It has a forward two-lobe LOX tank, a fully internal payload bay, and two quad-lobe LH2 tanks (one

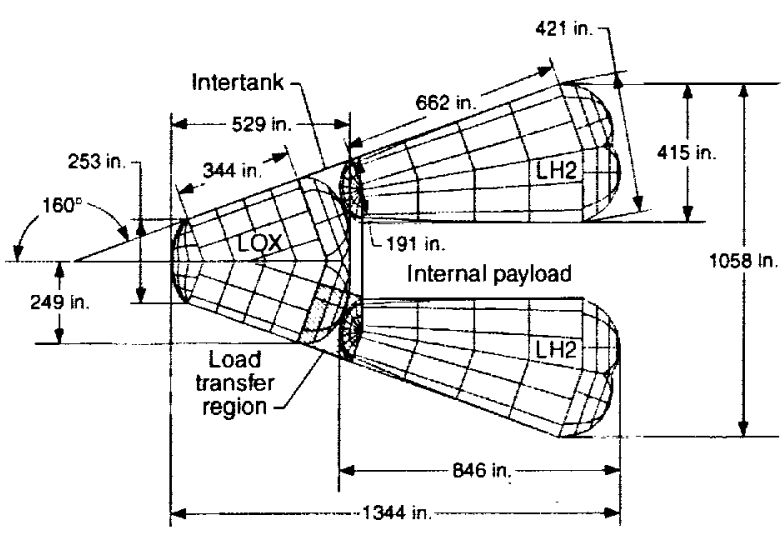

Figure $2 a .0023$ configuration with dimensions.

on each side of the payload bay). The intertank shell geometry is defined by the aft barrel-to-dome intersection on the forward LOX tank and the two forward barrel-to-dome intersections of the aft LH2 tanks. The perturbations made from the 0023 configuration in this study were anticipated to result in benefits to the vehicle, the airframe structure, or both. Although vehicle benefits can often be more significant than structural benefits, ${ }^{3}$ only structural assessments were performed in this study. The potential vehicle impacts are discussed but were not evaluated. The rationale for trying the major configuration perturbations considered is as follows:

1. Moving the payload bay external to the baseline vehicle OML improves the load paths through the vehicle tanks and intertanks and also allows single tanks to be used for both the LOX and LH2. Distributing the tank volume over the full width of the vehicle also results in a shorter tank, which results in a shorter vehicle and thus, increased vehicle packaging efficiency. The effect of head pressure on sizing is also reduced as the tank becomes shorter. Vehicle-kevel issues that should be addressed include total drag and lateral stability and control.

2. The benefit of having the LOX tank aft is the intertank and LH2 tank no longer have to support the large inertia loads associaled with the LOX fluid during launch and ascent. The result should be greatly reduced loads for sizing the interlank. If ullage pressure in the LH2 tank could be reduced (subject to propulsion system requirements), to reflect reduced pressure stabilization requirements, smaller skin gages could be used for the LH2 tank. The impact of the mass distribution and center-of-gravity location during flight would also have to be evaluated.

3. Increasing the vehicle fineness ratio, or decreasing the half-body angle, has the potential to improve aerodynamic performance, especially in reducing vehicle drag. It may also result in a more forward vehicle 
Table 1. Configuration Definition.

\begin{tabular}{|c|c|c|c|c|c|c|c|c|c|c|c|c|c|c|c|c|c|c|c|c|}
\hline \multirow{3}{*}{$\begin{array}{l}\text { Vehicle } \\
\text { Config. }\end{array}$} & \multirow{2}{*}{\multicolumn{3}{|c|}{$\begin{array}{c}\text { Fineness } \\
\text { Ratio }\end{array}$}} & \multirow{2}{*}{\multicolumn{3}{|c|}{$\begin{array}{c}\text { Payload } \\
\text { Bay }\end{array}$}} & \multirow{2}{*}{\multicolumn{2}{|c|}{$\begin{array}{c}\text { Fuel } \\
\text { Arrangement }\end{array}$}} & \multicolumn{5}{|c|}{ Number of Tanks } & \multicolumn{7}{|c|}{ Tank Shape/Arrangement } \\
\hline & & & & & & & & & \multicolumn{2}{|c|}{ LOX } & \multicolumn{3}{|c|}{$\mathrm{LH} 2$} & \multicolumn{2}{|c|}{ LOX } & \multicolumn{5}{|c|}{$\mathrm{LH} 2$} \\
\hline & Low & High & Dual & In & $\begin{array}{l}50 \% \\
\text { Out }\end{array}$ & $\begin{array}{l}100 \% \\
\text { Out }\end{array}$ & $\begin{array}{l}\text { LOX } \\
\text { Fwd }\end{array}$ & $\begin{array}{c}\text { LOX } \\
\text { Aft }\end{array}$ & 1 & 2 & 1 & 2 & 3 & $\begin{array}{c}2- \\
\text { Lobe }\end{array}$ & Conic & $\begin{array}{l}\text { Quad } \\
\text { Lohe }\end{array}$ & $\begin{array}{l}2- \\
\text { Lobe }\end{array}$ & $\begin{array}{c}3- \\
\text { Lobe }\end{array}$ & $\begin{array}{c}\text { 5- } \\
\text { Lobe }\end{array}$ & Conic \\
\hline 0023 & $\mathrm{x}$ & & & $\mathrm{X}$ & & & $\mathrm{X}$ & & $x$ & & & $\mathrm{X}$ & & $\mathrm{x}$ & & $\bar{x}$ & & & & \\
\hline LAI & $\mathrm{X}$ & & & $\mathrm{x}$ & & & & $\mathrm{x}$ & & $\mathrm{x}$ & & & $\mathrm{X}$ & $\mathrm{x}$ & & $\mathrm{x}$ & $\mathrm{x}$ & & & \\
\hline 0033 & $\mathrm{x}$ & & & & $x$ & & $\mathrm{x}$ & & $\mathrm{x}$ & & $\mathrm{X}$ & & & $x$ & & & & & $\mathrm{x}$ & \\
\hline HFLF & & $\mathrm{x}$ & & & & $\mathrm{x}$ & $\mathrm{x}$ & & $\mathrm{X}$ & & $\mathrm{X}$ & & & $\mathrm{x}$ & & & & $\mathrm{X}$ & & \\
\hline LL401 & & $\mathrm{x}$ & $\mathrm{x}$ & & & $x$ & $\mathrm{x}$ & & $x$ & & $\mathrm{X}$ & & & $\mathrm{x}$ & & & & $\mathrm{x}$ & & \\
\hline LL1B & & $\mathrm{x}$ & & & $\mathrm{x}$ & & $\mathrm{x}$ & & $\mathrm{x}$ & & & $\mathrm{x}$ & & $\mathrm{x}$ & & & & & & $\mathrm{x}$ \\
\hline 0028 & & $\mathrm{x}$ & & & & $\mathrm{X}$ & & $\mathrm{x}$ & & $\mathrm{x}$ & $\mathrm{x}$ & & & & $\mathrm{x}$ & & $\mathrm{x}$ & & & \\
\hline
\end{tabular}

center-of-gravity location, which would improve flight stability. This parameter impacts the aspect ratio of the tanks (ratio of width to length) and the resulting structural mass.

4. In order to minimize the amount of intertank structure, a goal would be to minimize the number of tanks required to contain the LOX and $\mathrm{LH} 2$. The particular geometry (cylindrical, conical, or lobed) of the tanks, coupled with the geometry of each vehicle configuration, ultimately determines the number of tanks required to package the LOX/LH2. The relationship between tank geometry and vehicle shape impacts the vehicle packaging efficiency and amount of TPS support structure required. ${ }^{3}$

5. As the number of lobes for a tank increases, the lobe intersection angle increases so the lobed tank more efficiently fills the cross-sectional area of the lifting body shape. Thus, for a specified cross-sectional tank area, the associated lobe radius can be decreased allowing the lobed tanks to be more efficiently packaged within the lifting body OML. This improves the overall vehicle packaging efficiency (which reduces vehicle weight). Increasing the number of lobes also should improve engine integration and thrust load paths, and reduce the amount of TPS support structure. However, increasing the number of lobes generally increases the weight associated with internal tension membranes and lobe skin joints.

The particular features of each configuration are summarized in Table 1. The structural sizing results in the present paper will be used to assess whether the potential benefits of the described features can actually be accrued.

\section{Derivation of Configurations}

The LAl (Figure 2b) is a LOX-aft configuration packaged within the 0023 OML (with fully internal pay-

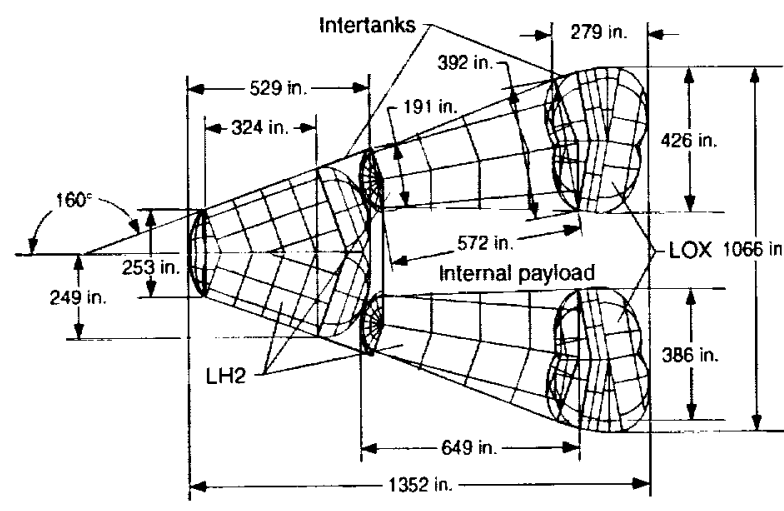

Figure $2 b$. LAI configuration with dimensions.

load bay). In the LA1 configuration, three LH2 tanks are required to obtain the total LH2 volume; one forward of the payload bay, and two running parallel to, and on each side of the payload bay. The two mid-LH2 tanks have inverted aft domes, which conform with the forward domes of the two two-lobe aft LOX tanks.

The 003.3 configuration (Figure $2 \mathrm{c}$ ), also derived from the 0023 , was packaged such that the payload bay is 50 percent external to the $0023 \mathrm{OML}$ and has the same body half angle ( 20 degrees) as the 0023. This allows the LH2 tank to be configured as a single 5-lohe tank, with the middle lobe having a smaller radius than the other lobes to accommodate the payload bay. As a result of having a single LH2 tank, the length of the total tank intertank stack for the 0033 configuration is 8 percent shorter than that of the 0023. (The effect of reducing the vehicle length on total vehicle weight is not assessed in this study.)

The 0028 configuration (Figure $2 d$ ) is a LOX-aft configuration (derived from the LAI) with a fully external payload bay (derived from the 0033) and with a body 


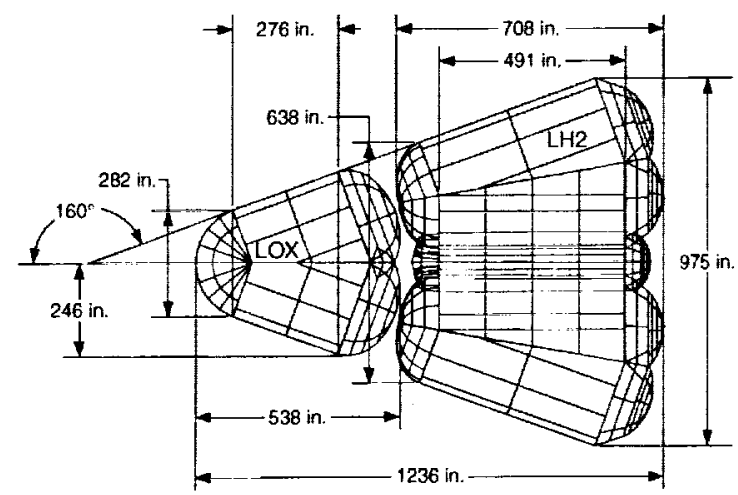

Figure 2c. 0033 configuration (external payload) with dimensions.

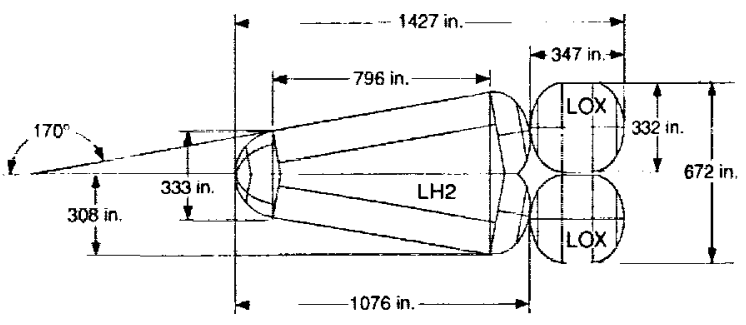

Figure $2 d .0028$ configuration (external payload) with dimensions.

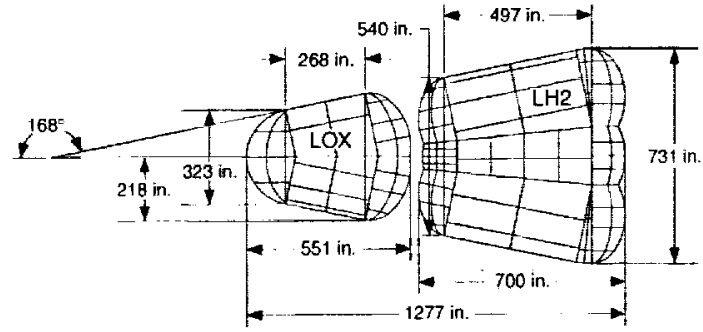

Figure 2e. HFLF configuration (external payload) with dimensions.

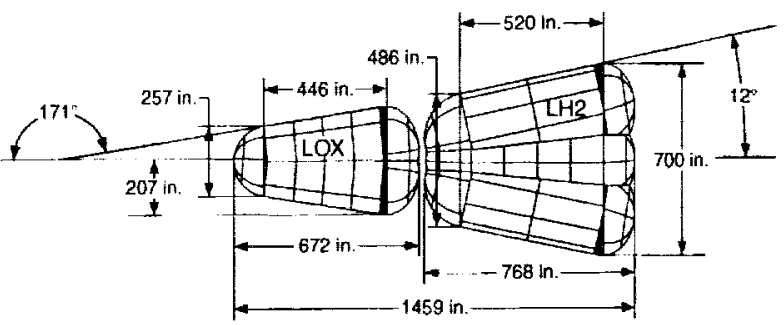

Figure $2 f . L L 40 I$ configuration (external payload) with dimensions. half angle of 10 degrees (compared to 20 degrees for the 0033). This allows a single LH2 tank to be used, as opposed to three $\mathrm{LH} 2$ tanks for the LA1 configuration.

The 0028 was repackaged as a LOX-forward configuration to obtain the HFLF configuration (having a single two-lobe forward LOX tank, and a single threelobe aft LH2 tank), as shown in Figure 2e. The tanks in the HFLF have better vehicle volumetric packaging efficiencies allowing the body half angle to be increased (compared to the 0028) from 10 degrees to 11.5 degrees. This resulted in the HFLF configuration becoming approximately 12 feet shorter in length than the 0028 .

The LL401 configuration (Figure $2 \mathrm{f}$ ) represents a vehicle derived from the HFLF, with an increased vehicle fineness ratio. This configuration was obtained by reducing the half body angle (of the HFLF) from 11.5 degrees to 9 degrees for the LOX tank. The half body angle is 11.5 degrees for the $\mathrm{LH} 2$ tank in both configurations although the LL401 LH2 tank is narrower at the forward and aft ends. As a result, the total length of the tanks and intertank stack was increased by 14 percent (a 22 percent increase in the LOX tank length, and a 10 percent increase in the $\mathrm{LH} 2$ tank length).

The LLIB configuration (Figure $2 \mathrm{~g}$ ) has a single two-lobe ogive-shaped LOX tank and two LH2 tanks, like the 0023 , which are conical instead of lobed. The half-body angle, 11.5 degrees, is identical to the HFLF and the $50 \%$ external payload bay is the same as the 0033. Because the conical tanks follow the vehicle OML, a dead space results in the center of the vehicle, and the LH2 tanks must he approximately 33 feet longer than the HFLF LH2 tank in order to satisfy volume requirements. The resulting impact on vehicle weight (due to reduced volumetric efficiency) was not assessed in this study. The configuration derivation history is summarized in Figure 3.

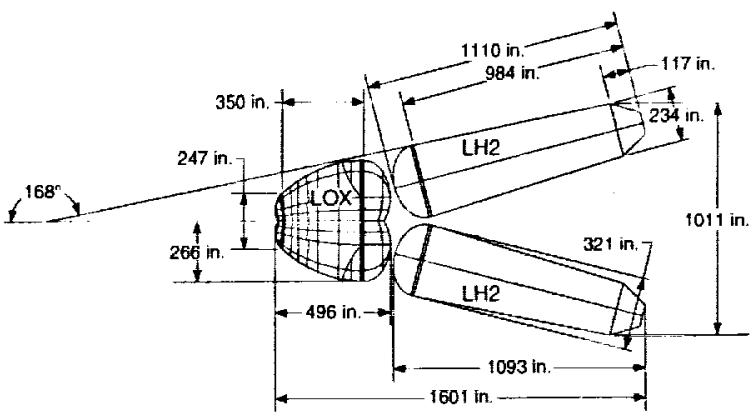

Figure 2g. LLIB configuration (external payload) with dimensions. 


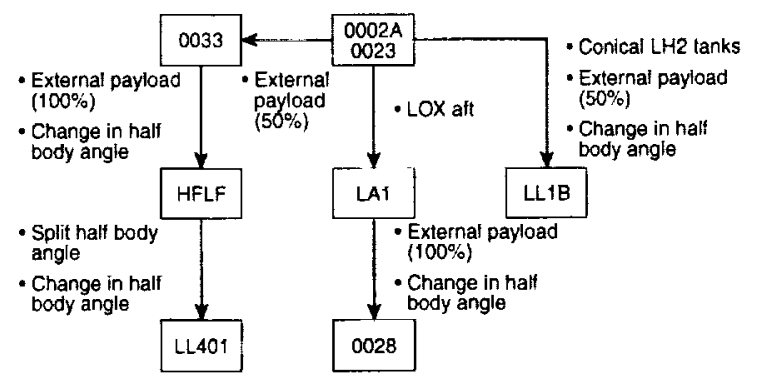

Figure 3. Configuration definition history.

\section{SIZING APPROACH}

A capability to size the cryogenic tanks and interconnecting intertanks was developed as part of this study. Gencral sizing relations were developed for the following tank components; the forward dome and dome joints, forward dome-to-barrel joint, barrel skin, Iongitudinal barrel skin $\mathrm{Y}$ joints, internal tension membranes, aft dome-to-barrel joint, and aft dome and dome joints (Figure 4). Tank feedlines and engine thrust structure attachment to the tanks are not considered in the present paper. Also, no circumferential harrel joints were assumed. Standard as well as inverted domes are included. The tanks are assumed to be pressure stabilized, with the pressure level sufficient to react longitudinal inertia loads, imposed by components that are forward of the particular tank, and any flight-induced bending loads, without compressive longitudinal stresses developing. ${ }^{4}$ In addition the lobed tanks are assumed to have longitudinal internal tension membranes which internally span the tank to connect opposing lobe intersections. These internal membranes eliminate bending due to pressurization loads in the tank barrel skins. As a result, initial structural sizing is based on strength, with stability checks (and resizing if required) performed when appropriate (on inverted domes and intertanks). The sizing relations are based on analytical relationships that are derived from structural mechanics and were obtained from a number of references. ${ }^{5.6,7}$ The relations account for differences or changes in component shape (number of lobes in a tank for example), size (length, width, radius, area, and/or volume), applied load levels (for intertanks and joints), pressure (LOX and LH2 tanks), and load gradients (joints and tank barrels). The general relationships are combined appropriately to reflect the structural arrangement of a particular vehicle configuration so that the effect of different tank geometries and packaging arrangements can be assessed in a preliminary level trade study.

\section{COMPONENT SIZING PROCESS}

The actual components that must be sized depend on the vehicle configuration definition and tank/intertank packaging. Based on the seven configurations developed for this study, sizing relations were required for the components shown in Figure 4. Materials assumptions, sizing criteria and sizing loads will be discussed in subsequent sections of the paper.

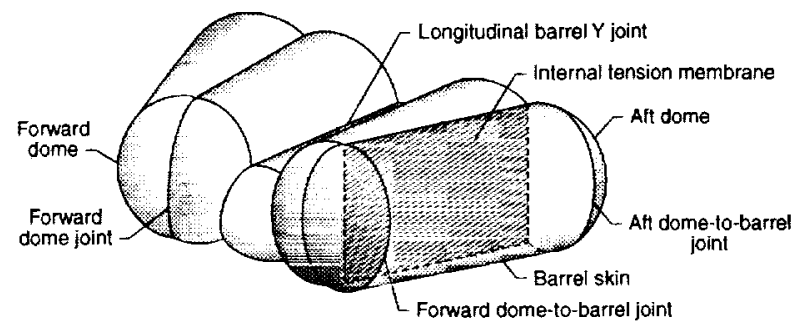

Figure 4. Structural componenst sized.

Joints

Preliminary sizing was performed by Lockheed Martin Michoud Space Systems (LMMSS) to estimate the weight of a 3-D Woven PMC Bonded Y-Joint concept as a function of tension running load across the joint for two load levels. At a running load of $2600 \mathrm{lb} / \mathrm{inch}$, the lineal weight was $0.36 \mathrm{lb} / \mathrm{inch}$; and at a running load of $8000 \mathrm{lb} / \mathrm{inch}$, the lineal weight was $1.10 \mathrm{lb} / \mathrm{inch}$. The weights of all the joints in the present study (longitudinal barrel, barrel-to-dome, and dome) are derived from these values according to the load level in the particular component. The total weight for a joint is obtained by multiplying the lineal weight by the total joint length. For the case of tank barrels, the barrel is divided into several segments, and the maximum value of circumferential load in each segment is used to obtain a lineal joint weight for that segment. This results in stepwise variation of joint weight in the barrel to reflect changes in total pressure, and/or radius.

\section{Forward Elliptical Dome and Joint}

Elliptical domes can be weight competitive with spherical domes and can improve overall vehicle packaging efficiency because of their lower profile. ${ }^{8}$ The dome geometry used throughout this study has an aspect ratio (major axis divided by minor axis) of 1.414 to minimize tank length without incurring compressive membrane stress under internal pressure. ${ }^{8}$ The forward elliptical dome and joint are sized for uniform ullage pressure. The maximum value of induced membrane loading used for sizing is a function of the total pressure 
and ellipse geometry and occurs at the dome apex. For barrels with multiple lobes, a joint is assumed where two elliptical domes intersect each other and the tank barrel tension membrane. The joint load is assumed to be identical to the membrane load that occurs at the dome apex, and the length of the elliptical dome intersection is used for joint sizing.

\section{Forward Dome-to-Barrel Joint}

The forward dome-to-barrel joint is sized based on the maximum membrane loading in the elliptical dome. The total joint length is based on the total of the partial lobe circumferences at the top of the barrel. Although additional stiffening (in the form of a heavy ring frame or a bulkhead) is usually needed in this region to react local kick loads, this stiffening structure was not sized in this study.

\section{Tank Barrel Lobes}

The tank barrels are assumed to be unstiffened partial conical sections that intersect to form lobes. Sizing parameters include pressure, tank length and lobe radii at both the forward and aft ends of the tanks. Uniform ullage pressure plus the local head pressure is used to derive the circumferential membrane load used for sizing. Currently, the barrel skins are subdivided into $3 \mathrm{sec}-$ tions along the length for barrel and $\mathrm{Y}$-joint sizing. The membrane loading is assumed to be uniform at any tank cross-section. Each section is sized for strength using the total (ullage plus head) pressure at the bottom of the section.

\section{Tank Barrel Longitudinal Y-Joint}

The circumferential membrane loading induced by ullage and head pressure is calculated at the bottom of each barrel section and used to derive the lincal joint weight for that barrel section. The appropriate lengths and joint weights of each section are used to calculate the tolal weight of longitudinal barrel joints.

\section{Tank Barrel Tension Membrane}

The tension membranes run the complete length of the tank barrel and span the interior between intersecting tank lobes. A dual-lobe tank would require a single tension membrane whereas a quad-lobe tank requires two (perpendicular) tension membranes. The running load magnitude in the membrane depends on the local circumferential load in the tank barrel as well as the local intersection angle of the lobes. Membranes are sized for strength. An additional constraint on membrane stiffness (to ensure tanks deflect without inducing bending at the lobe intersection) is not currently included.

\section{Aft Elliptical Dome and Joint}

The aft elliptical dome and joint are sized for uniform ullage plus total head pressure. The maximum value of induced membrane loading is used for sizing, and is a function of total pressure and ellipse geometry. The ellipse geometry assumed is the same as described previously. Two cases are considered; a standard dome, which can be strength sized, and an inverted dome, which can be sized for strength but must also be checked for stability (and dome thickness modified if necessary). Stability is checked (the required thickness) using equation (8) of reference 9 . Since barrels have multiple lobes, it is assumed that a joint is required where two elliptical domes intersect each other and the tank barrel tension membrane. The assumed joint load, the value that occurs at the dome apex, and the length of the elliptical dome intersection is used for sizing.

\section{Forward-to-Aft Tank Intertank}

The forward-to-aft intertank shell geometry is defined by aft barrel-to-dome intersection on the forward (either LOX or LH2) tank and the forward barrel-to-dome intersection of the aft (either LH2 or LOX) tank as shown in Figure 2a. The intertank shell is assumed to be sandwich construction, is continuous and encloses the volume between the tanks. Total load (due to forward tank weight plus fuel or oxidizer) is assumed to be divided equally and transferred through four regions of the intertank (two bottom and two top) as also shown in Figure $2 a$. Four load transfer regions are defined and assumed to be rectangular plates with simply supported edges for sizing. The load transfer regions are sized based on load (and use the higher density sandwich core), and the rest of the intertank is assumed to carry no load and have minimum gage face sheets (and use the lower density sandwich core). Strength sizing is used to calculate a total required laminate thickness. The total laminate thickness is divided between the two face sheets, and the (high-density) core thickness required to obtain the bending stiffness that meets stability requirements is calculated. The resulting core thickness is compared to a maximum-gage core thickness allowable, and if the calculated core thickness is less than the maximum thickness value, weights are calculated. If the calculated core thickness is greater than the maximum allowable, the maximum allowable core thickness is used and a new face sheet thickness (greater than required for strength) required to enforce stability is calculated and weights calculated for the design. The intertanks intersect the tank 
at the tank-wall/tank-dome interface. However, no sizing or weights were generated for the field joint that would also be required at these locations.

\section{Forward-to-Intermediate LH2 Intertank}

In the LAl configuration, a forward-to-intermediate LH2 intertank is required (see Figure $2 b$ ). The shell geometry is defined by the aft barrel-to-dome intersection on the forward LH2 tank, and the two forward barrel-to-dome intersections of the intermediate LH2 tanks. The intertank shell is assumed to be sandwich construction, is continuous and encloses the volume between the two intermediate LH2 tanks. Load calculation and distribution, and the sizing process is the same as described for the forward-to-aft intertank. As before, no field joints were sized for this location.

\section{Intermediate LH2-to-LOX Intertank}

The $\mathrm{LAl}$ configuration also requires intermediate LH2-to-LOX intertanks (see Figure 2b). The shell geometry is defined by the aft barrel-to-dome intersection on the intermediate LH2 tank and the two forward barrel-to-dome intersections of the aft LOX tanks. The intertank shell is assumed to be sandwich construction, is continuous and encloses the volume between the LOX and intermediate LH2 tanks. Total load for sizing is inertia due to forward LH2 tank weight plus fuel, forwardto-intermediate LH2 intertank, and intermediate LH2 tank weight plus fuel. Half of the total load is transferred through each of the intertanks. Because of the tank lobe orientation relative to the inertia load vector, the lobe closest to the vehicle centerline is assumed to carry a greater percentage of the load (60 percent) versus the outer lobe ( 40 percent). The sizing process is the same as described for the forward-to-aft intertank, and again, no manufacturing joints are assumed for the intertank.

\section{ASSUMPTIONS}

\section{Materials}

Quasi-isotropic (QI) properties for a representative polymer matrix composite (PMC) material system (IM7/ 977-2 for example) were used to size tank skins and intertank structure. No attempt was made to optimize the lay-ups for internal loads, since a complete set of critical load cases was not used for sizing. It is also assumed that sized laminates obey standard composite rules for balance and stacking sequence, which is easily achieved for quasi-isotropic laminates. Depending on the application, unnotched or notched strength allowables are used for sizing composite structures. ${ }^{10}$ However, for cryogenic tank applications, permeability of the LOX and/or LH2 through the tank walls continues to be an unresolved concern. Mitigation of the concern is currently addressed by imposing a limit strain allowable on the material for permeability. Concerns about permeability are also reflected in the minimum gage established for the tank wall laminates. The minimum gage for intertank structure is less than that for the tanks since permeability is not an issue. However, the design limit strain used for the intertank is the same as that used for the tank wall. It is assumed that the as-built tank barrel tension membranes will be sculpted rather than continuous sheets (which is assumed for sizing) and that the sculpted sheets will distribute the material such that minimum gage requirements are met. As a result, no minimum gage is enforced when sizing the tank internal tension membranes. The intertanks are assumed to be of sandwich construction with quasi-isotropic face sheets and a honeycomb core. A core density of $5 \mathrm{lbf} / \mathrm{ft}^{3}$ is used in the lightly loaded areas of the intertank, and a $10 \mathrm{lb} / \mathrm{ft}^{3}$ core is used in the intertank regions that are assumed to carry applied loading. Material properties and assumptions are summarized in Table 2.

Table 2. Material Properties and Specifications

\begin{tabular}{|c|c|}
\hline Property Description & Value \\
\hline \multicolumn{2}{|l|}{ Ouasi-Isotropic PMC Laminates } \\
\hline Young's Modulus (Msi) & 8.8300 \\
\hline Shear Modulus (Msi) & $3 . .3700$ \\
\hline Poisson's Ratio & 0.3100 \\
\hline Ply Thickness (inches) & 0.0055 \\
\hline Density $\left(\mathrm{lb} / \mathrm{in}^{3}\right)$ & 0.0570 \\
\hline Limit Strain (tension/compression) & 0.0060 \\
\hline Minimum Gage - Tanks (inches) & 0.066 (12 plies) \\
\hline Minimum Gage - Intertanks (inches) & 0.044 (8 plies) \\
\hline Minimum Gage - Tension Membranes & Not Enforced \\
\hline \multicolumn{2}{|l|}{ Honevcomb Core } \\
\hline Density for Load $<1000 \mathrm{lb} /$ inch (lb/in 3 & 5.0 \\
\hline Density for Load > $1000 \mathrm{lh} /$ inch (lh/in & 10.0 \\
\hline Maximum Thickness (inches) & 3.0 \\
\hline
\end{tabular}

\section{Loads}

In this study, limit loads on tank pressure and inertia were used for sizing (for consistency with limit material strain). Sizing was limited to the liftoff and initial occurrence of maximum acceleration ascent load cases. At maximum acceleration, the LOX and LH2 tanks are assumed to be half full with densified propellants and at the same absolute ullage pressure as at liftoff. Loads and acceleration factors are summarized in Table 3. 
Table 3. Loads and Load Factors

\begin{tabular}{lc}
\hline \multicolumn{1}{c}{ Property Description } & Value \\
\hline Axial Limit Load Factors & 1.355 \\
\hline Launch (g's) & 3 \\
Maximum Acceleration (g's) & \\
\hline Fuel Densities & 78.2 \\
\hline LOX @ $-320^{\circ} \mathrm{F}\left(\mathrm{lb} / \mathrm{ft}^{3}\right)$ & 4.75 \\
LH2 @ -434 ${ }^{\circ} \mathrm{F}\left(\mathrm{lb} / \mathrm{ft}^{3}\right)$ & \\
\hline Nominal Ullage Gage Pressure $\left(\mathrm{lb} / \mathrm{in}^{2}\right)$ & \\
Maximum Axial Acceleration (LOX and LH2) & 34.1 \\
Launch (LOX and LH2) & 25.3 \\
\hline \hline
\end{tabular}

\section{SIZING CALIBRATION RESULTS}

The weight of a quad-lobe $\mathrm{LH} 2$ tank has been calculated by LMMSS for a LOX-forward configuration and resulted in nominally 24 ply laminates in the tank barrel skins and the tension membranes. A weight statement is also available from LMSW for the same LH2 tank configuration. A comparison of the weights obtained from the various quad lobe LH2 tank sizings performed by LMSW, LMMSS and LaRC have been tabulated in Table 4.

One difficulty in comparing weights is not having a complete definition of what is included under each item. Another difficulty results from different approaches used by LMSW and LMMSS in defining bulkheads: LMSW assumes internal bulkheads at both the forward and aft dome-to-barrel intersections, whereas LMMSS assumes heavily reinforced external ring frames at the same location. At this point, it is not certain if one approach would be lighter than the other, and for comparison purposes, it is assumed that the two approaches result in identical total bulkhead weights. These bulkheads are not currently sized with the LaRC process.

The total tank weights are comparable, with LaRC being slightly lighter than both Michoud and LMSW. In the LaRC process, the membranes and longitudinal barrel Y-joints are tapered according to pressure and tank radius. This results in the $\mathrm{LaRC}$ membrane weight being lighter than the LMSW membrane. When equivalent groups of components are compared (at the bottom of the table) the weights agree fairly closely for the Rings + Bulkheads. For the forward dome + barrel skins + membranes, the LaRC weight is less than the Michoud weight and is assumed to be due to tapering the membranes in the LaRC process. The LMSW weight is substantially larger for these items. The LMSW fore-to-aft barrel Y-joint weight is substantially lighter than that of
Table 4. Comparison of Quad-Lobe LH2 Tank Weights

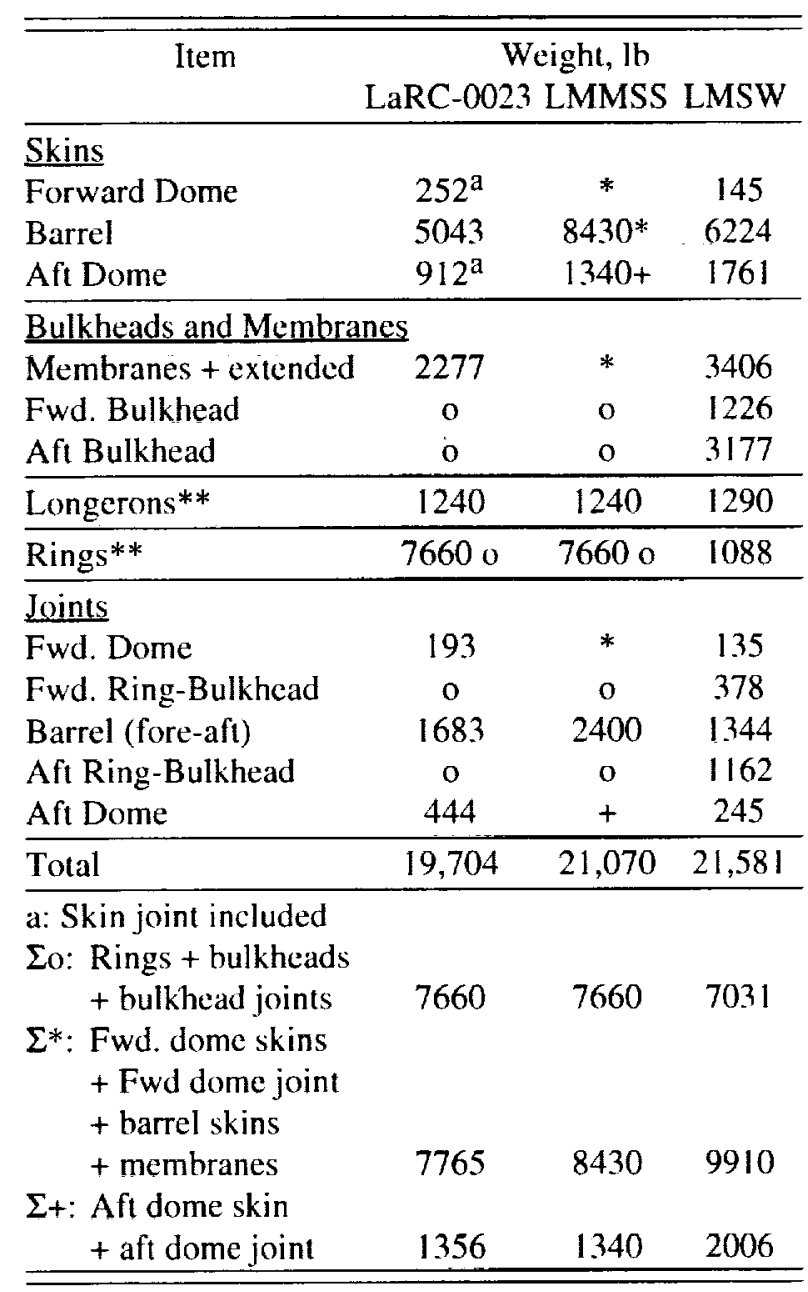

**Longerons, frames and bulkheads not sized by LaRC, LMMSS values used.

LaRC and Michoud, and LaRC is somewhat lighter than Michoud because of tapering.

In reference 3, intertank weight for a LOX forward configuration is presented as a function of component size and loading. A composite honeycomb sandwich intertank is used to connect the aft bulkhead of the vehicle LOX tank to the forward bulkhead of the vehicle LH2 tanks. A finite element model was generated for the intertank (including the bulkheads) and strength and stability failure modes were used as sizing constraints in a NASTRAN Optimization analysis. For the reference vehicle in that study, ${ }^{3}$ the intertank is 15.3 feet long and has a total intertank structural weight of $10360 \mathrm{lb}$, including a 1.5 non-optimum factor. The intertank sized in reference 3 is compared to the 0023 intertank sized using the current process (taking into account the non-optimum factor and area ratio for the inter- 
Table 5. Comparison of Intertank Weights

\begin{tabular}{lcc}
\hline \multicolumn{1}{c}{ Item } & \multicolumn{2}{c}{ Weight, lb } \\
& LaRC-0023 & Reference 3 \\
\hline Forward Bulkhead & N/A & 1759 \\
Aft Bulkhead & N/A & 1303 \\
Internal Beam/Web Structure & N/A & 456 \\
Sandwich Shell & 2719 & 2997 \\
\hline
\end{tabular}

tank sandwich shells) in Table 5 . The weights of the various items making up the intertank sized in reference 3 are also shown in the table. For the sandwich shell portion of the intertank (which is the only item sized in the process described in this paper), very good correlation is obtained between the two sizing methods. The 0023 intertank uses $10 \mathrm{Ibf} / \mathrm{ft}^{3} 2.5$ inch-thick core in the four loaded regions and $5 \mathrm{lbf} / \mathrm{ft}^{3} 1.5$ inch-thick core in the minimum gage regions. In reference 3 , a $5.5 \mathrm{lbf} / \mathrm{ft}^{3}$ core is used for the entire sandwich shell. Table 5 also shows that the two bulkheads (one at each end of the intertank), not sized in the current process, weigh as much as the shell structure. ${ }^{3}$

\section{SIZING RESULTS AND COMPARISONS}

\section{Structural Weights}

The sizing data for all seven configurations, having equivalent total LOX and $\mathrm{LH} 2$ tank volumes, are summarized in Table 6 . The 0023 configuration has the lightest LOX tank for all of the LOX-forward configurations.
It also has one of the heavier total LH2 tank weights, mainly due to having two tanks and the associated increase in total tank surface area, internal tension membranes and barrel joints. It has the lightest (for LOX forward and no inverted domes) intertank because the load path from the LOX to the LH2 tank is assumed to pass through a narrow region of the structure resulting in most of the intertank being lightly loaded and thus, lightweight.

The LOX tanks for the 0023 and 0033 are very similar in shape and surface area and have identical weights. Because the single LH2 tank in the 0033 has five Iobes, there is a great deal of weight associated with internal tension membranes, barrel lobe joints, dome-to-barrel joints and dome-to-dome joints. As a result, the LH2 tank weights for the two configurations only differ by 2 percent. Because of the load path area assumed through the intertank, the 0023 intertank is 42 percent lighter than the 0033 intertank, resulting in the 0023 being a lighter configuration (by 6.5 percent).

The two LOX-Aft configurations are the 0028 and the LAI. The 0028 was the lightest weight of all configurations whereas the LAI was the second heaviest. Two cylindrical LOX tanks (see Figure 2d) were located aft of the LH2 tank in the 0028. The three LH2 tanks in the LA I configuration are much heavier than the single $\mathrm{LH} 2$ tank in the 0028 configuration due to two primary factors; much greater tank skin surface area, and much greater total joint length. Although both configurations have two LOX tanks (with equivalent total surface areas), the

Table 6. Configuration Sizing Results

\begin{tabular}{|c|c|c|c|c|c|c|c|}
\hline & \multicolumn{7}{|c|}{ Vehicle Configuration } \\
\hline & 0023 & 0033 & HFLF & LL401 & LAl & 0028 & LLIB \\
\hline \multicolumn{8}{|c|}{ Vehicle ComponentTotals } \\
\hline Area $\left(\mathrm{ft}^{2}\right)$ & 18837 & 18336 & 16519 & 16700 & 24243 & 18830 & 21022 \\
\hline Weight (lb) & 25482 & 27253 & 25031 & 26328 & 31170 & 22490 & 23211 \\
\hline Areal Weight $\left(\mathrm{lb} / \mathrm{ft}^{2}\right)$ & 1.35 & 1.49 & 1.52 & 1.58 & 1.29 & 1.19 & 1.10 \\
\hline \multicolumn{8}{|l|}{ LOX Tank(s) } \\
\hline Area $\left(\mathrm{ft}^{2}\right)$ & 4566 & 4506 & 4606 & 4878 & 5478 & 5498 & 4911 \\
\hline Weight (lb) & 7226 & 7287 & 7532 & 8724 & 8075 & 6706 & 7290 \\
\hline Areal Weight $\left(\mathrm{lb} / \mathrm{ft}^{2}\right)$ & 1.58 & 1.62 & 1.64 & 1.79 & 1.47 & 0.82 & $\mathrm{I} .48$ \\
\hline \multicolumn{8}{|l|}{ LH2 Tank(s) } \\
\hline Area $\left(\mathrm{ft}^{2}\right)$ & 12534 & 11434 & 9349 & 9304 & 16541 & 10452 & 13595 \\
\hline Weight (lb) & 15537 & 15227 & 12971 & 13328 & 20964 & 12957 & 11001 \\
\hline Areal Weight $\left(\mathrm{Ib} / \mathrm{ft}^{2}\right)$ & 1.24 & 1.33 & 1.39 & 1.43 & 1.27 & 1.24 & 0.81 \\
\hline \multicolumn{8}{|l|}{ Intertank(s) } \\
\hline & 1736 & 2396 & 2564 & 2519 & 2224 & 2880 & 2516 \\
\hline & 2719 & 4739 & 4528 & 4276 & 2131 & 2827 & 4920 \\
\hline Areal Weight $\left(\mathrm{lb} / \mathrm{ft}^{2}\right)$ & 1.57 & 1.98 & 1.77 & 1.70 & 0.96 & 0.98 & 1.96 \\
\hline
\end{tabular}


cylindrical tanks in the 0028 configuration are significantly lighter because barrel and dome joints are not required (as they are for the two-lobe tanks in the LAI configuration).

The weight of the LAI configuration is greater than the weight of the 0023 LOX-forward configuration. This is mainly due to the increased LOX and LH2 tank weights resulting from the increased surface areas required to package equivalent fuel volumes in the $0023 \mathrm{OML}$. Although the LAI configuration has three intertanks (one forward and two intermediate) the total intertank weight is lighter than that of the 0023 configuration because the large inertia loads due to the LOX fuel are no longer sizing the structure. In fact, in the LAl configuration, all of the intertanks are minimum gage structure.

Although the two cylindrical LOX tanks in the 0028 have more total surface area than the single two-lobe tank in the HFLF, the HFLF tank is approximately 12 percent heavier. The increased weight is due to the internal tension membrane and the lobe barrel joints required for the HFLF. The HFLF LH2 tank is shorter and wider than the $0028 \mathrm{LH} 2$ tank, resulting in less surface area and thus, less weight in the barrel skins. However, the HFLF tank has two internal tension membranes, four sets of lobe barrel joints and longer runs of barrel-todome joints resulting in these items being heavier than the corresponding ones for the 0028 . In total, the differences in tank barrel and membrane/joint weights offset each other so that both LH2 tanks had identical weights. The largest difference in weight between the two configurations occurred in the intertanks. Because the HFLF intertank must support the inertia of the LOX during launch and ascent, its intertank was 60 percent heavier than the 0028 intertank and is the main reason the HFLF is heavier.

The LLIB is the lightest LOX-forward configuration. The LOX tank weights are approximately equal for the LLIB and HFLF configurations with the HFLF being slightly heavier, mostly duc to joint weight. Although the single LH2 tank in the HFLF has significantly less surface area than the two tanks in the LL1B, the total weight of the HFLF LH2 tank is approximately 18 percent heavier. The LLIB barrels are almost twice the weight of the HFLF barrel (corresponding to twice the surface area), but the internal tension membranes, lobe barrel joints and long lengths of barrel-to-dome joints in the HFLF configuration overwhelm the savings in barrel weight. The intertanks have identical surface areas, but the HFLF intertank is approximately 8 percent lighter because of a slightly better load path.
The HFLF LOX tank forward dome is heavier than that of the LL401 because the tank is wider at the domebarrel intersection and as a result, has a larger radius. The LL401 LOX tank barrel is longer and narrower than that of the HFLF, has more surface area, and consequently is $1.300 \mathrm{lb}$. heavier. The net effect is that the LL40 I LOX tank is approximately 16 percent heavier than the HFLF tank. The LH2 tanks for the two configurations have identical surface areas and very similar dimensions resulting in only about a 3 percent difference in weight. The intertanks for the two configurations were also similar in size and dimensions with the LL401 intertank being approximately 6 percent lighter. In total, the HFLF configuration was 5 percent lighter than the LL40I configuration.

\section{Sensitivity Studies}

For LOX forward configurations, the large ullage pressure in the LH2 tanks ( 40 psia) is required to pressure stabilize the tanks and the pressure level is dictated by the large LOX inertia loading. An advantage of the LOX Aft configuration is that the LH2 tanks do not have to be designed to react the large inertia force (due to the weight of the LOX fuel) and the ullage pressure could potentially be reduced. A sensitivity study performed to study the effect of reducing $\mathrm{LH} 2$ tank ullage pressure on the weight of the LA1 configuration is shown in Figure 5 . The results show that a reduction in ullage pressure, to $22.4 \mathrm{psig}$, leads to a total weight equal to that of the 0023. For further reductions in ullage pressure, the LA I configuration is lighter than the 0023 configuration. At approximately $24 \mathrm{psig}$, the LH 2 tank barrels reach minimum gage, with the reduction in LH2 tank weight at lower ullage pressures resulting from a continuing decrease in the tank joint weight (where no minimum area has been specified).

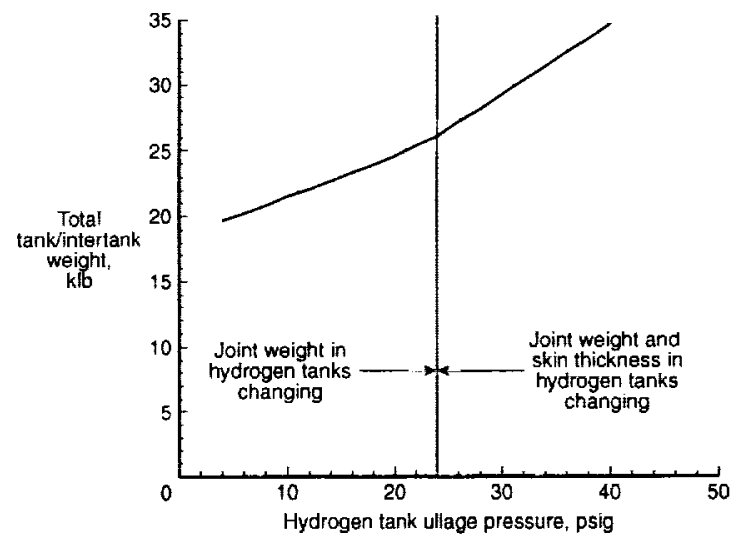

Figure 5. Effect of LH2 tank ullage pressure on total weight (Configuration LAI). 


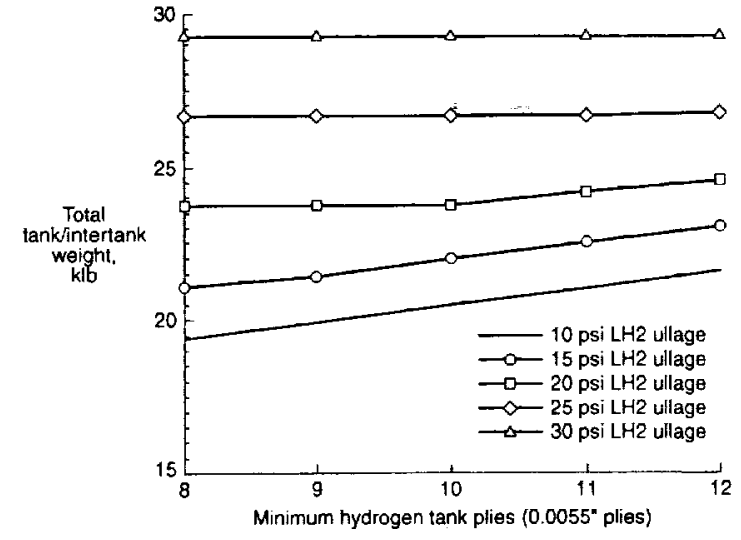

Figure 6. Effect of minimum gage on total weight (Configuration LAI).

Decreases in tank skin weight as ullage pressure is reduced are limited by the tank skin minimum gage. A sensitivity study was performed on the LA I configuration to determine the effect of tank skin minimum gage on tank weight and minimum desirable ullage pressure. Further decreases in tank weight are possible as the minimum gage is reduced from 12 to 8 plies, as shown in Figure 6.

A sensitivity study was performed to assess the effect of varying the core densities and maximum allowable core thicknesses in the intertank for the 0023 configuration. For a uniform core thickness throughout the intertank, the intertank weight increases as the core density increases as expected (Figure 7). For a uniform core density and thickness, as the core thickncss is decreased, the face sheet thickness must be resized to meet the stability requirement. As the core thickness is decreased from an initial value of 3 inches, the intertank weight decreases for all three core densities, reaching a minimum

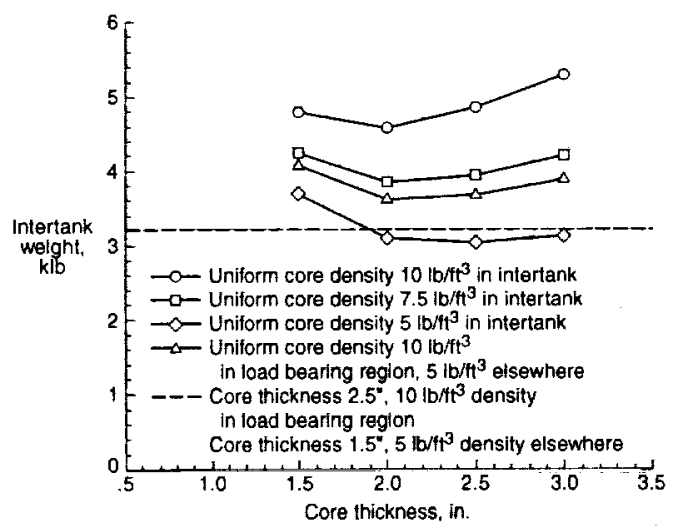

Figure 7. Effect of intertank core thickness and density on intertank weight (Configuration 0023). weight at a core thickness between 2.0 and 2.5 inches (depending on the core density). A more realistic design might be onc where the heavier $\left(10 \mathrm{lb} / \mathrm{ft}^{3}\right)$ core is used in the four load carrying regions of the intertank, and the lighter $\left(5 \mathrm{lb} / \mathrm{ft}^{3}\right)$ core is used in the minimum gage areas. The minimum weight for this design is $3629 \mathrm{lb}$. and is associated with a core thickness of 2.0 inches and total face sheet thickness of 0.127 inches. If the core thickness is also optimized in the load-carrying region, the intertank weight reduces to $3208 \mathrm{lb}$. and the optimum thickness is 2.5 inches in the load-carrying region.

\section{OBSERVATIONS AND CONCLUSIONS}

A tank and intertank sizing tool that includes effects of major design drivers, and which allows parametric studies to be performed, has been developed and calibrated against independent representative results. Although additional design features, such as bulkheads and field joints, are not currently included in the process, the improved level of fidelity has allowed parametric studies to be performed which have resulted in understanding of key tank and intertank design drivers, design sensitivities, and definition of preferred design spaces.

The sizing results demonstrated that there were many interactions between the configuration parameters of internal/external payload, vehicle fineness ratio (half body angle), fuel arrangement (LOX-forward/LOX-aft), number of tanks, and tank shape/arrangement (number of lobes). Because these interactions can be quite strong, there are no absolute statements that can be made about a particular parameter.

With fuel arrangement for example, the lightest and the second heaviest configurations were both LOX-aft; the 0028 and the LAI, respectively. The difference between the two is that the 0028 has a fully external payload bay, allowing a single LH2 tank, whereas the LA I configuration has a fully internal payload bay. Because of the large volume of $\mathrm{LH} 2$ required for the SSTO RLV, three tanks are required to package the LH2 in the LAI, a forward (of the payload bay) tank and two mid-body tanks, one on each side of the payload bay. The resulting total LH2 tank weight is 62 percent greater than the weight for the single 0028 tank. Thus, if the payload bay is internal, LOX-forward configurations are lighter than LOX-aft (0023 versus LA1). However, if the payload bay is external, LOX-aft configurations are lighter than LOX-forward (0028 versus all others).

In general, for a given tank geometry/configuration, minimum weight is achieved by minimizing the number 
of tanks. For lobed LH2 tanks, the weights of the single LH2 tanks (in configurations 0028, HFLF, LL401 and 0033 ) are all less than the weight of the two-tank configuration (0023) which is less than the three-tank configuration (LA1). Similarly, for lobed LOX tanks, the single tanks in configurations LL1B, HFLF, 0023 and 0033 were all lighter than the two two-lobe tanks in the LAI configuration. However, if the half body angle becomes too small (resulting in long narrow tanks), a single tank also becomes less efficient and can be very heavy; the single LOX tank in the LL40I was the heaviest of all the lobed configurations.

The weight efficiency of the lobed tanks is a function of the half-body angle as well as the ratio of tank length to maximum width (at the base). The half-body angle gives a trapezoidal-shaped tank planform with the tank width at the top being smaller than the tank width at the bottom. In general, lobed tank weight is minimized as the ratios of tank top-width to bottom-width, and the length-to-maximum-width both approach unity. Thus, the longer and narrower LL401 LOX tank is considerably heavier than the shorter and squatter 0023, 0033 and HFLF tanks. This trend is complicated when the number of lobes in the tanks also varies because of the impact of varying the number of tension membranes, total length of lobe barrel joints, and total length of barrel-to-dome joints. For example, the longer and narrower two-lobe LH2 tank in the 0028 configuration weighs approximately the same as the shorter and squatter threelobe tanks in the HFLF and LL401 configurations. However, the $0033 \mathrm{LH} 2$ tank is much wider at the base than it is long, and consequently is significantly heavier than the HFLF and LL401 tanks. The fact that it is a fivelobe, versus three-lobe tank also tends to increase the weight.

The weight efficiency of the lobed tank also varies with the number of lobes. As the number of lobes increases, the weight associated with increasing the number of tension membranes, total length of lobe barrel joints, and total length of barrel-to-dome joints also increases. Thus the four and five lobe LH2 tanks are heavier than the 2 and 3 lobe tanks. However, this trend does not seem to be as strong as the geometry trends discussed in the previous paragraph. For example, the two-lobed 0028 tank weight is the same as the weights of the HFLF and LL401 3-lobed tanks.

In general, cylindrical or conical tanks will be lighter than lobed tanks because internal tension membranes, longitudinal tank skin (lobe) joints, and dome joints are not required. The two cylindrical LOX tanks in the 0028 configuration are lighter than the two lobed tanks in the
LA1 configuration, and the two conical LH2 tanks in the LLIB configuration are lighter than all of the lobed tank configurations. However, cylindrical tanks do not package efficiently in the lifting body shape, and the resulting impact on vehicle weight would have to be included to assess the viability of cylindrical tanks. It is likely that cylindrical tanks would also require additional TPS support structure, which would also increase the weight of the total system.

The 0028 configuration appears to be a good point of departure for developing a minimum weight configuration. There is freedom to adjust the half-body angle to some extent to optimize aerodynamic performance (lift, drag, and controllability) without significantly impacting structural weight. The LOX aft and fully external payload bay features of this configuration are desirable to minimize weight. Replacing the two cylindrical LOX tanks with a single 3-lobe tank would improve the volumetric efficiency of the vehicle and reduce the amount of TPS support structure needed. A single 3-lobe LOX tank would also shorten the tank length (and thus the vehicle length), reduce the head length of the LOX (potentially resulting in a lighter tank weight), and better integrate with the engine thrust structure of the linear aerospike engine. Although inverting the aft domes of the LH2 tank would result in a shorter vehicle (potentially reducing vehicle weight) and save structural weight by virtually eliminating the intertank, the difference in number of lobes for the two tanks could result in a more complicated intertank geometry (which would have to be assessed). The intertank could be completely eliminated by using a common bulkhead between the LH2 and LOX tanks.

The tank minimum gage value is currently larger than the value for non-tank structures due to permeability concerns. Tank weights in the LOX-Aft configurations can be further reduced if the minimum gage value can be reduced. Thus, it is very important to establish and verify (by test) the true minimum gage value for tanks. In addition, joints may be easier to design, manufacture and assemble, as well as being more robust, for the LOX-Aft configuration with reduced ullage pressures, due to the reduction in design load required for the joint.

\section{ACKNOWLEDGMENTS}

The authors would like to thank Lockheed Martin Skunkworks and Michoud Systems for providing tank configuration and weights information. 


\section{REFERENCES}

1. Cook, S. A.: "The X-33 Advanced Technology Demonstrator”, AIAA-96-1195, April 1996.

2. Lockwood, Mary Kae: Overview of Conceptual Design of Early VentureStar ${ }^{\mathrm{TM}}$ Configurations. Presented at the 38th Aerosciences Meeting and Exhibit, January 10-13, 2000/ Reno NV. Available as AIAA 2000-1042.

3. Dorsey, John T.; Wu, K. Chauncey; Rivers, Kevin; Martin, Carl; and Smith, Russell: Airframe Integration Trade Studies for a Reusable Launch Vehicle. Presented at the 1999 Space Technology \& Applications International Forum (STAIF-99) Conference on Next Generation Launch Vehicles. January 31 - February 4, 1999, Albuquerque, NM.

4. Huzel, Dieter K.; and Huang, David H.: Design of Liquid Propellant Rocket Engines (Second Edition). NASA SP-125, 1971.

5. Baker, E. H.; Kovalevsky, L.; and Rish, F. L.: Structural Analysis of Shells. Robert E. Krieger Publishing Company, Malabar, Florida, 1986.
6. Roark, Raymond J.; and Young, Warren C.: Formulas for Stress and Strain (Fifth Edition). McGrawHill Book Company, New York, 1982.

7. Brush, Don O.; and Almroth, Bo O.: Buckling of Bars, Plates, and Shells. McGraw-Hill Book Company, New York, 1975.

8. Wu, K Chauncey; and Lepsch, Roger A. Jr.: Nontangent, Developed Contour Bulkheads For A WingBody Single Stage Launch Vehicle. Presented at the $37^{\text {th }}$ AIAA Aerospace Sciences Meeting and Exhibit, January 11-14, 1999 / Reno, NV. Available as AIAA $99-$ 0835 .

9. Weingarten, V. I.; and Seide, P.: Buckling of ThinWalled Double Curved Shells (NASA Space Vehicle Design Criteria, Structures). NASA SP-8032, August 1969.

10. Niu, Michael C. Y.: Composite Airframe Structures. Conmilit Press Ltd., Hong Kong, 1992. 
